\title{
Acute Effect of Neuromuscular Electrical Stimulation on Oxidative Stress and Hematological Parameters in Critical Patients
}

Luana Carneiro Ribeiro ${ }^{1,2}$, Thamara C N Amaral ${ }^{1,2}$, Adriano Flourencio Vilaça ${ }^{1,2}$, Marthley José Correia Costa ${ }^{3}$, Ubiracé Fernando Elihimas Júnior ${ }^{2}$, Marco Aurélio Valois Correia Júnior ${ }^{4}$, Célia Maria Machado Barbosa de Castro ${ }^{1}$, Maria do Amparo Andrade ${ }^{1}$, and Eduardo Eriko Tenório de França ${ }^{1,2}, 3^{\star}$

1Universidade Federal de Pernambuco (UFPE)-Recife (PE), Brazil

${ }^{2}$ Hospital Agamenom Magalhães -HAM-Recife (PE), Brazil

${ }^{3}$ Universidade Católica de Pernambuco-UNICAP-Recife (PE), Brazil

${ }^{4}$ Universidade de Pernambuco (UPE)-Recife (PE), Brazil

"Corresponding author: Eduardo Eriko Tenório de França, Department of Physiotherapy, Hospital Agamemnon Magalhães, Estrada do Arraial, Casa Amarela, s/n, Recife (PE), Brazil, E-mail: edueriko@hotmail.com

Received date: August 26, 2017; Accepted date: September 27, 2017; Published date: September 30, 2017

Copyright: $(2017$ Ribeiro LC, et al. This is an open-access article distributed under the terms of the Creative Commons Attribution License, which permits unrestricted use, distribution, and reproduction in any medium, provided the original author and source are credited.

\section{Abstract}

Aims: To analyze oxidative cellular stress and monitor the evolution of hematological parameters before and after of neuromuscular electrical stimulation (NMES) in critically ill patients.

Methods: A controlled and randomized clinical trial, composed of a sample of 19 patients, admitted to the Agamenon Magalhães Hospital intensive care unit. The patients were divided into two groups: NMES group ( $\mathrm{n}=9$ ), patients that underwent only one NMES in the quadriceps muscle for $20 \mathrm{~min}$, and the other, control group ( $\mathrm{n}=10$ ) that did undergo any therapeutic intervention.

Results: In relation to the demographic and clinical variables, the groups were homogeneous at the beginning of the study. For the nitric oxide (NO) analysis, we perceived a reduction, when comparing the before and after analyses, in NO in the stimulated cell $(p=0.0188)$ and non-stimulated cell $(p=0.0258)$ in the NMES group. Also in relation to NO, when comparing the two groups, we observed a significant reduction in the NMES group compared to the control one. For the hematological parameters we did not observe any difference when comparing before and after in the two groups studied.

Conclusion: We can conclude that the use of NMES causes a reduction in cellular NO levels, showing the beneficial effects in reducing oxidative stress. With relation to complete blood count, we observed that its application was not able to causes any alterations.

Keywords: Nitric oxide; Reactive species of oxygen and nitrogen; Physiotherapy in intensive care and physical exercise

\section{Introduction}

Prolonged periods of immobilization cause severe disorders in the ostheomyoarticular system, which are more and more frequent in critically ill patients that need mechanical ventilation (MV) for long periods due to underlying diseases and the adverse effects of medications $[1,2]$.

Bed rest and longer dependency on MV can adversely affect various organs and systems, having the following consequences: muscular contraction; worsening of functional physical condition; reduction in maximum oxygen consumption $\left(\mathrm{VO}_{2} \max \right)$; muscular weakness acquired in the intensive care unit (ICU); deep vein thrombosis; pressure ulcers; pneumonia associated with mechanical ventilation (PAV); atelectasis; bone demineralization; and alterations in emotional state, such as anxiety, apathy, depression, and emotional lability [3].

Muscular weakness, so common in critically ill patients, is associated with inflammatory deregulation that seems to contribute to the appearance of myopathy. The mechanism for muscular decay due to immobility has not yet been completely clarified. Two molecular interactions are implied: oxidative stress and selected proinflammatory cytokines. It is believed that this synergy between oxidative stress, inflammatory cytokines, and inactivity cause or accelerate muscular hypotrophy $[4,5]$.

Oxidative stress via reactive species of oxygen (RSO) and nitric oxide (NO) is able to cause oxidative damage in the DNA, in the lipids and proteins, thus being one of causes of muscular disorder and degradation. Various oxidant agents can contribute to inflammatory damage to muscles. Superoxide ion $\left(\mathrm{O}_{2^{-}}\right)$, NO, and hydrolyzed radicals $(\mathrm{OH}-)$ are examples of RSO [6].

Various studies have been developed with the aim of preventing the detrimental effects of paresis acquired in ICU or minimizing it, such as alternative therapy. Among the proposed procedures, passive mobilization and/or active exercises stand out, as well as the application of neuromuscular electrical stimulation (NMES), daily suspension of sedation and a reduction in the infusion of medications such as neuromuscular blockers (NMB) and corticosteroids, maintenance of electrolyte homeostasis, and adequate nutritional intake [7].

The NMES is a feature widely used in early mobilization protocols in critically ill patients and has several benefits on attenuation of 
muscle mass loss and functional improvement. Thus, it is believed that its effects can contribute to minimize the damage caused by immobility and critical illness, by reducing oxidative stress. Thus, this study aims to analyze oxidative cellular stress and the evolution of hematological parameters before and after the use of NMES in critical patients.

\section{Methods}

The study is a controlled and randomized clinical trial, composed of a sample of 19 individuals, of both genders, admitted to the Agamenom Magalhães Hospital, ICU in mechanical ventilation, and is an integral part of another study entitled "Acute effect of physical exercise associated with electrical muscular stimulation on oxidative stress and immunological system parameters in critically ill patients", under CAAE number "04563612.5.0000.5197", and already approved by the ethics committee, under approval number "61991".

The study included patients submitted to MV that presented a good: cardiovascular reserve, demonstrated by a $<20 \%$ variability in heart rate (HR) at rest, systolic blood pressure (SBP) $<200 \mathrm{mmHg}$ or $>90 \mathrm{mmHg}$, normal electrocardiogram (without evidence of acute myocardial infarction or arrhythmias); respiratory reserve, demonstrated by peripheral oxygen saturation $\left(\mathrm{SpO}_{2}\right)>90 \%$ and inspired oxygen fraction $\left(\mathrm{FiO}_{2}\right)<60 \%$, without signs of respiratory discomfort and a respiratory rate $(\mathrm{RR})<25 \mathrm{ipm}$ and clinical parameters were included on the study, such as: haemoglobin stable and $>7 \mathrm{~g} / \mathrm{dL}$, platelet count stable and $>20,000$ cells $/ \mathrm{mm}^{3}$, white cell count $4,300-10,800 \mathrm{cells} / \mathrm{mm}^{3}$, body temperature $<38^{\circ} \mathrm{C}$, blood glucose level $3.5-20 \mathrm{mmol} / \mathrm{L}$, patient appearance, pain, fatigue, shortness of breath, emotional status acceptable, stable conscious state, no other neurological contraindications, no orthopaedic contraindications, no recent SSG/ flap to lower limbs or trunk, medically stable if DVT and/or PE, excessive weight able to be safely managed, no attachments that contraindicate mobilisation, safe environment, appropriate staffing and expertise and patient consent.

Excluded from the study were patients that presented: inability to walk without assistance before acute illness in ICU, under $21 \mathrm{~s}$, pregnant women, patients with a body mass index $(\mathrm{BMI})>35 \mathrm{Kg} / \mathrm{m}^{2}$, neuromuscular and vascular disease, a history of cerebral vascular accidents, lesions on the skin where the electrode is placed, unconsolidated fractures, a cardiac pacemaker, and that had undergone cancer therapy in the last 6 months.

After recruiting the individuals for the study, they were evaluated using medical records, demographic information, clinical history, diagnostic, and BMI. Data was also collected on the use of neuromuscular blockers, sedatives, and vasoactive drugs. Collection began after acceptance by the Ethics and Research Committee of the Institution and those legally responsible for the patients signing an Informed Consent Form.

After this initial evaluation, the patients eligible for the study had 10 $\mathrm{mL}$ of venous blood collected via central venous access, before the procedure and one hour after carrying out the NMES protocol and for the control group, the two blood samples were collected with a one hour interval, without there being any intervention between them. 10 $\mathrm{mL}$ of each venous blood sample were used with vacuum tubes (Vacutainer') with dipotassium EDTA, where the hematological parameters were analyzed at the hospital's own laboratory and the oxidative stress analysis was carried out using nitric oxide at the Keizo Asami Immunology Laboratory (KAIL) at the Federal University of Pernambuco.
The evaluation of NO release was performed using the GRIESS method. Then, $50 \mu \mathrm{l}$ of the GRIESS reagent (1 g of sulfanilamide, Sigma 9251, $0.1 \mathrm{~g}$ of N-(Naphthyl) Ethylenediamine DihydrochlorideSigma 5889, $2.5 \mathrm{ml}$ of PA phosphoric acid and distilled water of 100 $\mathrm{ml}$ ) were added. The plate was incubated for $10 \mathrm{~min}$ in the dark. The reading was performed at $540 \mathrm{~nm}$ in Elisa reader (Dynatech MR 5000). The sensitivity threshold of the test was $1.56 \mu \mathrm{M}$.

The randomization for participation in the study was carried out randomly using the Microsoft Office Excel program version 2007. The study population was divided into two groups: control $(n=10)$, patients that did not undergo any type of therapeutic intervention at the time of carrying out the study protocol, and NMES $(n=9)$, patients submitted to neuromuscular electrical stimulation of both quadriceps muscles.

The patients that were randomized for the NMES group of lower limbs used the current in the quadriceps muscle (vastus medialis and lateralis), with the NMES moderate intensity protocol. The electrodes were placed on this muscle and the NMES was the (4 Channel Neurodyn; Ibramed; São Paulo, Brazil), which was programmed for muscular strengthening with a pulse width of $500 \mu \mathrm{sec}$, rate of $50 \mathrm{~Hz}, 2$ $\mathrm{s}$ elevation, $5 \mathrm{~s}$ sustainment, and $2 \mathrm{~s}$ decrease, with an ON/OFF time of 1:1. The current intensity was established via visible muscular contraction and if this visualization was not possible, palpation of the stimulated muscle was carried out. The duration of the session was 20 min for each stimulated quadriceps muscle, with NMES being carried out on the two quadriceps of both MMII at the same time (Figure 1) [8].

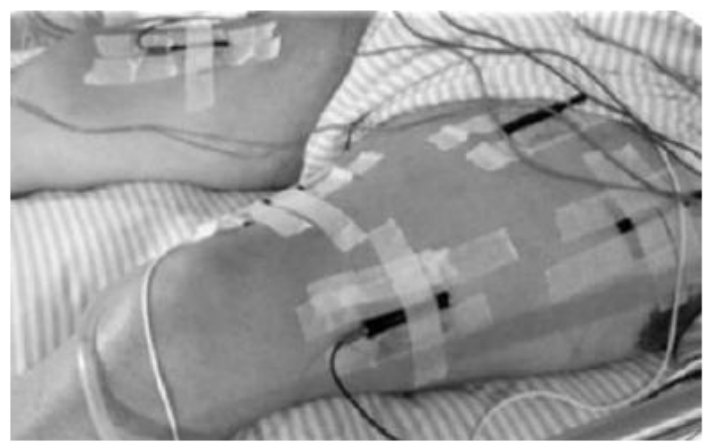

Figure 1: Illustration of neuromuscular electrical stimulation (NMES) application on lower limbs in critical patients under mechanical ventilation. Source: Archive of images of the author.

All results and demographic characteristics were assessed using the GraphPadPrism 4 software and Microsoft Office Excel 2007. The presentation of the measured variables was performed through tables and figures. Median and the percentile (25-75\%) were used to present continuous variables, while categorical data were presented using absolute and relative frequencies.

By testing the normality assumption of involved variables in the study, the Shapiro-Wilk test was used. The comparative analysis between two groups was performed using the Mann-Whitney test and the Wilcoxon test was used to compare the same group. The relation between variables was performed using the Spearman correlation (non-normal distribution). All findings were considered at a $5 \%$ significance level. 
Page 3 of 7

\section{Results}

During the period from December 2013 to February 2016, 465 patients with various pathologies were admitted into general ICU, of which 402 did not meet the criteria for inclusion in the study, with the other 63 patients being enrolled and randomized into the two groups. However, 44 patients met the criteria for exclusion from the study and only 19 completed the analyses (Figure 2 ).

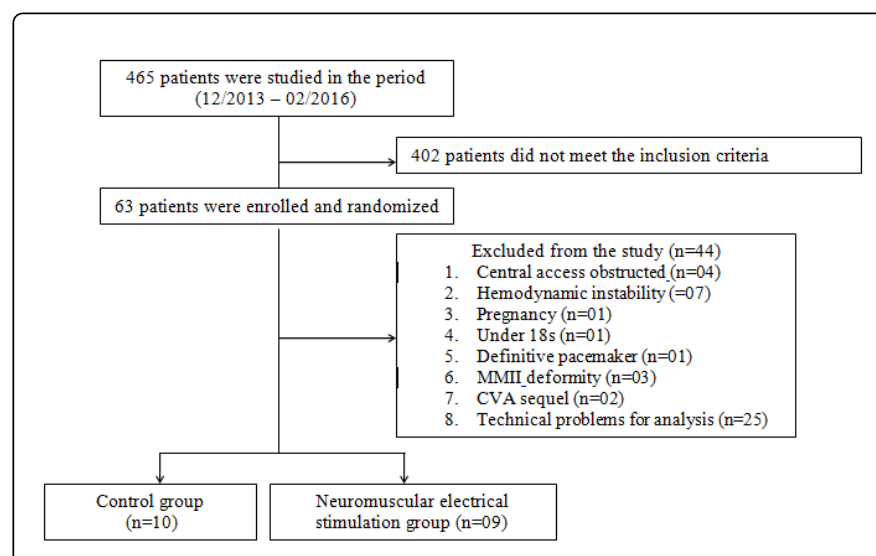

Figure 2: Flowchart of patients that took part in the study.

Table 1 presents median and percentile (25-75\%) of the demographic and clinical variables of each of the two groups studied; control and NMES. The variables analyzed were: age, height, weight, BMI, APACHE II (Acute Physiology and Chronic Health Evaluation), fluid balance $(\mathrm{FB})$ in the last $24 \mathrm{~h}$, RASS (Richmond Agitation Sedation Scale), time in bed rest, in mechanical ventilation (MV), admitted to the intensive care unit (ICU), hemoglucotest (HGT), respiratory system compliance (Cst), and respiratory system resistance (Rsr). For all of the variables studied no significant differences were observed, which demonstrates homogeneity between the two groups at the beginning of the study.

Table 2 demonstrates the rates of median and percentile (25-75\%) of the variables for the CBC parameters, before and one hour after the study protocol for each group studied, where no significant difference was observed at any time studied for both groups. The variables analyzed for the $\mathrm{CBC}$ were: leukocytes, erythrocytes, hemoglobins, hematocrits, platelets, neutrophils, and monocytes.

Table 3 shows the NO behavior in the evaluated groups. In the control group, no significant difference was observed in NO concentrations, when before and after were compared, both in the stimulated cells, positive control $(\mathrm{C}+)$ and in the non-stimulated cells, negative control (C-). In the neuromuscular electrical stimulation (NMES) group, a significant reduction in NO concentrations was observed both for the $\mathrm{C}+$ and the $\mathrm{C}$-, when before and after were compared.

Figures $3 \mathrm{a}$ and $3 \mathrm{~b}$ represent the results obtained based on the NO analysis, collected before and after the study protocol for stimulated monocytes, positive controls $(\mathrm{C}+)$ and non-stimulated monocytes, negative control (C-) for both groups. In these figures a reduction in variation in $\mathrm{NO}$ production is perceived in the stimulated monocyte $(\mathrm{p}=0.003)$ and the non-stimulated monocyte $(\mathrm{p}=0.003)$ after the use of NMES, compared to the control group.

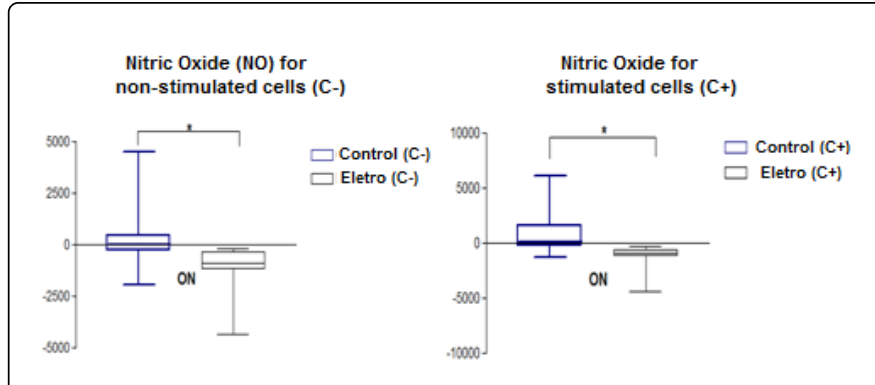

Figures 3: Averages \pm standard deviations in nitric oxide (NO) values for the stimulated cell positive control $(\mathrm{C}+)$ and nonstimulated cell (C-), for the two groups studied: control and NMES. ${ }^{\star}$ Mann-Whitney Test for independent samples. Differences between the control group and the NMES group $3 \mathrm{a}\left({ }^{*} \mathrm{p}=0.003\right)$ and $3 \mathrm{~b}$. $\left({ }^{*} \mathrm{p}=0.003\right)$.

\section{Discussion}

In the period in which the patients remained bed ridden, transformations occur in the muscular fibers for type II, including a reduction in oxidative ability, mitochondrial density, and blood capillaries. Moreover, cardiovascular performance is reduced, due to the smaller volume of systolic ejection and increase in heart rate. There is venous stasis, due to the reduction in muscular pump activity in the limbs and increase in the risk of developing thrombosis [9]. The period of bed rest may also contribute to bone demineralization, which contributes to a succession of osteoporosis and renal calculus, and a reduction in sodium and water in the body [9].

In this study, the values described in Table 1 demonstrate that no differences were observed in the demographic and clinical characteristics of the patients in the two groups studied, which characterizes the homogeneity between the groups for all the evaluated parameters. This homogeneity between the groups is important, since it does not expose any of the two groups studied to a higher risk factor for comprising their clinical condition. Muscular disorder in the critically ill is quite an apparent clinical condition in patients undergoing long periods of MV and ICU admittance. The magnitude of acquired muscular weakness in ICU is extremely variable and exhibits an intimate connection with time of bed rest and exposure to risk factors, such as nutritional status and MV dependency $[3,10]$.

There are few studies in the literature that describe the effects of NMES on hematological parameters applied to critically ill patients, however, various other benefits of this intervention have already been widely proven, especially with regards to easing loss to muscular mass and improving functionality. In this study the behavior of this intervention was evaluated for bed ridden patients suffering from immobility, a highly common situation in patients undergoing MV and admitted to ICU. Various effects contribute to muscular weakness, of which bed rest itself stands out, along with an increase in oxidative stress, an increase in inflammatory cytokines, and nutritional status [6].

In Table 2, we evaluate CBC behavior of the blood collected before and after the study protocol in the two groups studied. Thus, for all of the cells evaluated in the $\mathrm{CBC}$, no type of alteration was shown, when comparing before and after the procedure. These results demonstrate that NMES applied to critically ill patients does not provoke alterations 
Citation: Ribeiro LC, Amaral TCN, Vilaça AF, Costa MJC, Elihimas Júnior UF, et al. (2017) Acute Effect of Neuromuscular Electrical Stimulation on Oxidative Stress and Hematological Parameters in Critical Patients. J Immuno Biol 2: 131. doi:10.4172/2476-1966.1000131

Page 4 of 7

in hematological parameters, thus being considered a safe technique that can be applied with causing hematological damage to critically ill patients.

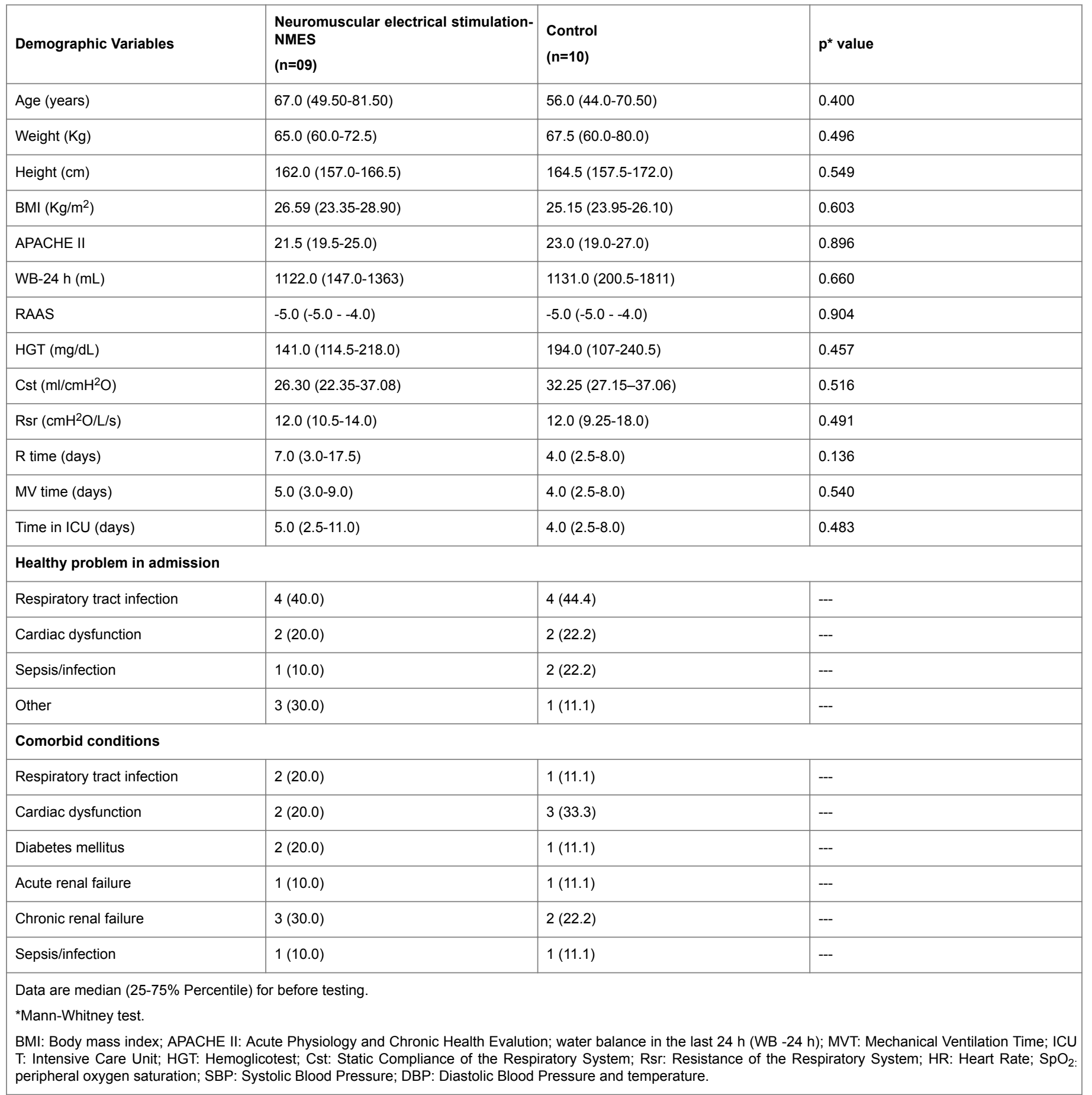

Table 1: Average demographic and clinical variables evaluated at the beginning of the study comparing the two groups studied: control and NMES.

"Khaty Stiller [11] defined a series of safety criteria for mobilizing critically ill patients, including a good cardiovascular reserve, respiratory reserve, and favorable clinical criteria, including number of leukocytes, hemoglobins, and platelet count. Currently, NMES is considered an integral part of early mobilization programs, especially used in the initial stages of mobilization". Our finding add to the safety criteria established by Kathy Stiller, since they demonstrate that NMES initiated using minimum safety criteria does not cause any risk via 
Citation: Ribeiro LC, Amaral TCN, Vilaça AF, Costa MJC, Elihimas Júnior UF, et al. (2017) Acute Effect of Neuromuscular Electrical Stimulation on Oxidative Stress and Hematological Parameters in Critical Patients. J Immuno Biol 2: 131. doi:10.4172/2476-1966.1000131

Page 5 of 7

significant changes in hematological parameters in critically ill patients.

\begin{tabular}{|c|c|c|c|c|c|}
\hline \multirow[t]{3}{*}{ Complete Blood Count } & \multicolumn{4}{|l|}{ Group } & \\
\hline & \multicolumn{2}{|l|}{ Control $(n=10)$} & \multicolumn{2}{|l|}{ NMES ( $n=9)$} & \\
\hline & Before & After & Before & After & \\
\hline \multirow[t]{2}{*}{ Leukocytes $\left(10^{3} / \mu \mathrm{L}\right)$} & $\begin{array}{l}10.65 \\
(7.60-16.05)\end{array}$ & $\begin{array}{l}11.80 \\
(7.35-17.40)\end{array}$ & $\begin{array}{l}13.50 \\
(9.450-24.35)\end{array}$ & $\begin{array}{l}13.10 \\
(9.05-25.65)\end{array}$ & \\
\hline & $p=0.893$ & \multicolumn{2}{|l|}{$\mathrm{p}=0.899$} & $\mathrm{p}^{*}$ value & \\
\hline \multirow[t]{2}{*}{ Erythrocytes $\left(10^{6} / \mu \mathrm{L}\right)$} & $\begin{array}{l}2.94 \\
(2.59-4.29)\end{array}$ & $\begin{array}{l}2.79 \\
(2.54-4.30)\end{array}$ & $\begin{array}{l}3.12 \\
(2.635-3.695)\end{array}$ & $\begin{array}{l}3.040 \\
(2.775-3.615)\end{array}$ & \\
\hline & $p=0.190$ & \multicolumn{2}{|l|}{$p=0.912$} & $\mathrm{p}^{*}$ value & \\
\hline \multirow[t]{2}{*}{ Hematocrits (\%) } & $\begin{array}{l}25.90 \\
(22.70-37.75)\end{array}$ & $\begin{array}{l}24.50 \\
(22.20-38.10)\end{array}$ & $\begin{array}{l}28.90 \\
(23.75-33.05)\end{array}$ & $\begin{array}{l}27.90 \\
(25.60-32.40)\end{array}$ & \\
\hline & $p=0.262$ & \multicolumn{2}{|l|}{$\mathrm{p}=0.903$} & $\mathrm{p}^{*}$ value & \\
\hline \multirow[t]{2}{*}{$\begin{array}{l}\text { Platelets } \\
\left(10^{3} / \mu \mathrm{L}\right)\end{array}$} & $\begin{array}{l}187.5 \\
(109.5-373.0)\end{array}$ & $\begin{array}{l}207.5 \\
(111.0-376.0)\end{array}$ & $\begin{array}{l}219.0 \\
(144.5-359.0)\end{array}$ & $\begin{array}{l}214.0 \\
(130.0-313.5)\end{array}$ & \\
\hline & $p=0.948$ & \multicolumn{2}{|l|}{$\mathrm{p}=0.302$} & $\mathrm{p}^{*}$ value & \\
\hline \multirow[t]{2}{*}{ Neutrofiles (\%) } & $\begin{array}{l}73.95 \\
(70.55-86.80)\end{array}$ & $\begin{array}{l}76.70 \\
(71.15-84.70)\end{array}$ & $\begin{array}{l}76.25 \\
(70.10-89.25)\end{array}$ & $\begin{array}{l}81.65 \\
(71.0-91.3)\end{array}$ & \\
\hline & $p=0.431$ & \multicolumn{2}{|l|}{$p=0.134$} & $\mathrm{p}^{*}$ value & \\
\hline \multirow[t]{2}{*}{ Lymphocytes (\%) } & $\begin{array}{l}13.50 \\
(10.25-17.85)\end{array}$ & $\begin{array}{l}13.10 \\
(8.90-14.45)\end{array}$ & $\begin{array}{l}10.90 \\
(4.35-12.95)\end{array}$ & $\begin{array}{l}8.80 \\
(3.30-11.80)\end{array}$ & \\
\hline & $p=0.264$ & \multicolumn{2}{|l|}{$p=0.137$} & $\mathrm{p}^{*}$ value & \\
\hline \multirow[t]{2}{*}{ Monocytes (\%) } & $\begin{array}{l}4.50 \\
(2.95-11.25)\end{array}$ & $\begin{array}{l}4.65 \\
(2.78-9.35)\end{array}$ & $\begin{array}{l}3.70 \\
(1.70-6.70)\end{array}$ & $\begin{array}{l}2.80 \\
(1.55-6.35)\end{array}$ & \\
\hline & $\mathrm{p}=0.394$ & \multicolumn{2}{|l|}{$p=0.252$} & $\mathrm{p}^{*}$ value & \\
\hline \multicolumn{6}{|c|}{ Values written in bold are statistically significant. } \\
\hline \multicolumn{6}{|c|}{$\begin{array}{l}\text { Using the CBC, leukocyte count, erythrocytes, hemoglobins, hematocrits, platelets, neutrofiles, lymphocytes, and monocytes were evaluated. Groups: control and } \\
\text { neuromuscular electrical stimulation (NMES). }\end{array}$} \\
\hline
\end{tabular}

Table 2: $\mathrm{CBC}$ analysis evaluated before and 1 hour after the study protocol comparing the two groups studied: control and neuromuscular electrical stimulation (NMES).

Some evidence suggests that inactivity can contribute to an inflammatory response. Pro-inflammatory cytokines and oxidative stress have been investigated as potential causes for the muscular weakness associated with acute critical illness. In response to this important clinical implication the rehabilitation process is one of the most studied forms of prevention in current literature. The role of oxidative stress and inflammatory cytokines in musculature has been studied in laboratories in animal models. It is believed that activity can change the inflammatory cellular message in healthy people [6].

In Table 3, we can evaluate the behavior of oxidative stress via nitric oxide (NO). We observe that in the control there were no changes in $\mathrm{NO}$ values, both for the positive control $(\mathrm{C}+)$ and the negative control
(C-), when comparing before and after carrying out the study protocol. On the other hand, in analyzing the values for $(\mathrm{C}+)$ and $(\mathrm{C}-)$, and comparing before and after the application of NMES, we can observe that NMES was able to significantly reduce the NO values in both. Thus, this study could indicate a probable NMES protector effect in reducing oxidative cellular stress in the population studied.

Figures $3 \mathrm{a}$ and $3 \mathrm{~b}$ demonstrate that both for the stimulated monocytes $(\mathrm{C}+)$ and for the non-stimulated monocytes $(\mathrm{C}-)$, in analyzing the presence of $\mathrm{NO}$, we observe a reduction in $\mathrm{NO}$ values, when we compare the NMES group of quadriceps with the control group, considering the fall in NO values before and after carrying out 
the procedure, a phenomenon that was not observed in the control group.

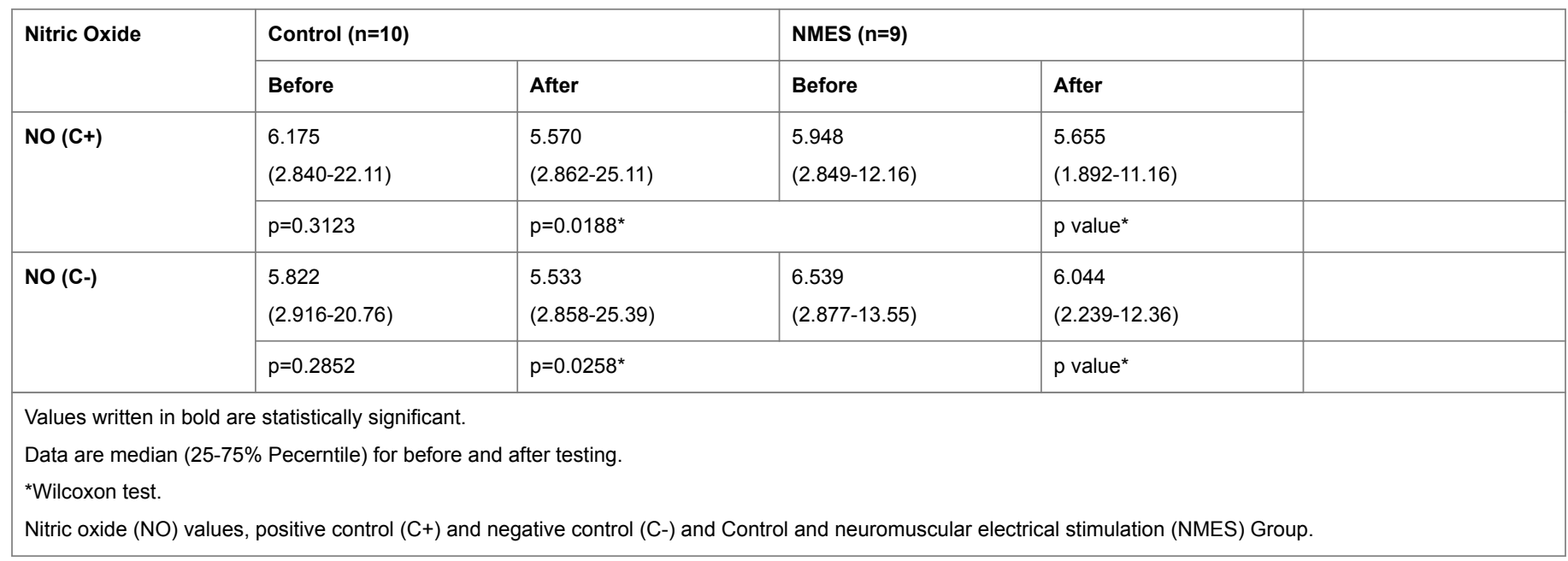

Table 3: Values for nitric oxide cultivated in monoxide, with the stimulated cell, positive control $(\mathrm{C}+)$ and with the non-stimulated cell, negative control (C-), evaluating before and after for the groups studied.

Critically ill patients are vulnerable to synthesis of oxidizing agents and a reduction in anti-oxidizing agents [12]. Oxidative stress is also known for increasing oxidation, playing an important role in the physiopathological process of muscular disorder. RSO provides lipid peroxidation, since it leads to the liberation for toxins and arachidonic acid derivates that damage the cellular membrane, deactivating receptors and enzymes in the membrane and altering the ionic chemical response. Products of cellular destruction by RSO produce a positive feedback, generating more RSO. At the same time, the interaction between RSO and cytokines and other intercellular molecules is associated with muscular degradation [12].

These findings suggest a potential beneficial effect of NMES in reducing the oxidative stress applied to critical patients, and can be considered as a moderate intensity muscular contraction activity for this type of patient, providing a positive alteration in the redox status of cells and tissues, by reducing baseline levels of oxidative damage and increasing resistance to oxidative stress [13-15], considered to have a beneficial effect on health. In fact, exercise considered as being of moderate intensity, carried out regularly, results in adaptations in antioxidant capacity, which protects cells against the detrimental effects oxidative stress, preventing subsequent cellular damage [16,17].

Our results correlate with the findings of Evi et al. [18], who by evaluating different exercise intensities and their effects on oxidative stress immediately after and $4 \mathrm{~h}$ after a cycloergometer test with a maximum workload of $60 \%$, in patients with chronic pulmonary obstructive disease (CPOD), observed that there was a systemic reduction in the induction of oxidative stress brought on by exercise, especially after sub-maximal exercises.

Gerovasili et al. [19] verified that NMES applied early in critically ill patients was able to induce acute effects over systemic microcirculation. These effects were demonstrated via an increase in blood perfusion in the thenar musculature, verified using a proximal infrared spectroscopy device, immediately after applying NMES for 45 min. The systemic effect of NMES in this study was proven by the ability to improve tissue perfusion in muscular groups that were distant from the electro-stimulated one, with the potential for preventing polineuromyopathy in critically ill patients being attributed to the technique. This hypothesis was based on the existence of studies that demonstrate the possible effect of NMES in freeing antiinflammatory mediators in the stimulated location, which can subsequently be distributed in the blood current, promoting an increase in perfusion in muscular groups from a distance [20,21].

This probable NMES protector effect compared to the control group in relation to the NO found in this study, is in agreement with the study from Reese et al., [22], who studied the effects of NMES associated with a manipulated diet on oxidative stress in patients with progressive multiple sclerosis and observed a reduction in oxidative stress and excito-toxicity associated with large functional gains in these patients.

It is still very early for us to be able to reach any conclusion regarding our findings. Our results demonstrated that NMES applied to critically ill patients does not provoke alterations in hematological parameters, it thus being considered a safe technique that can be applied without hematological damage to critically ill patients. We can also conclude that NMES, with moderate intensity exercise parameters, was enough to reduce NO cellular levels in this group of patients compared to the control group, showing the beneficial effects of NMES in reducing oxidative stress for the population studied. These findings reinforce the contribution of this therapy in reducing the detrimental effects of immobilization, especially in patients that are under the effect of sedation and MV without carrying out any type of activity.

\section{References}

1. Chiang LL, Wang LY, Wu CP, Wu HD, Wu YT (2006) Effects of Physical Training on Functional Status in Patients With Prolonged Mechanical Ventilation. Phys Ther 86: 1271-1281.

2. De Jonghe B, Bastuji-Garin S, Durand MC, Malissin I, Rodrigues P, et al. (2007) Respiratory weakness is associated with limb weakness and delayed weaning in critical illness. Crit Care Med 35: 2007-2015. 
Citation: Ribeiro LC, Amaral TCN, Vilaça AF, Costa MJC, Elihimas Júnior UF, et al. (2017) Acute Effect of Neuromuscular Electrical Stimulation on Oxidative Stress and Hematological Parameters in Critical Patients. J Immuno Biol 2: 131. doi:10.4172/2476-1966.1000131

Page 7 of 7

3. De Jonghe B, Sharshar T, Lefaucheur JP, Authier FJ, Durand-Zaleski I, et al. (2002) Paresis acquired in the intensive care unit: a prospective multicenter study. JAMA 288: 2859-2867.

4. Mador MJ, Bozkanat E (2001) Skeletal muscle dysfunction in chronic obstructive pulmonary disease. Respir Res 2: 216-224.

5. Duscha BD, Annex BH, Green HJ, Pippen AM, Kraus WE (2002) Deconditioning fails to explain peripheral skeletal muscle alterations in men with chronic heart failure. J Am Coll Cardiol 39: 1170-1174.

6. Winkelman C (2007) Inactivity and Inflammation in the Critically Ill Patient. Crit Care Clin 23: 21-34.

7. Bax L, Staes F, Verhagen A (2005) Does neuromuscular electrical stimulation strengthen the quadriceps femoris? A systematic review of randomised controlled trials. Sports Med 35:191-212.

8. Falavigna LF, Silva MG, Freitas AL, Silva PF, Paiva Júnior MD, et al. (2013) Effects of electrical muscle stimulation early in the quadriceps and tibialis anterior muscle of critically ill patients. Physiother Theory Pract 30: 223-228.

9. Nava S, Piaggi G, De Mattia E, Carlucci A (2002) Muscle retraining in the ICU patients. Minerva Anestesiol 68: 341-345.

10. Latronico N, Rasulo FA (2010) Presentation and management of ICU myopathy and neuropathy. Curr Opin Crit Care 16: 123-127.

11. Stiller K (2007) Safety issues that should be considered when mobilizing critically ill patients. Crit Care Clin 23: 35-53.

12. Li YP, Schwartz RJ, Waddell ID, Holloway BR, Reid MB (1998) Skeletal muscle myocytes undergo protein loss and reactive oxygen-mediated NFkappaB activation in response to tumor necrosis factor alpha. FASEB J 12: 871-880.

13. Niess AM, Dickhuth HH, Northoff H, Fehrenbach E (1999) Free radicals and oxida- tive stress in exercise--immunological aspects. Exerc Immunol Rev 5: 22-56.
14. Di Meo S, Venditti P (2001) Mitochondria in exerci-se-induced oxidative stress. Biol Signals Recept 10: 125-140.

15. Cooper CE, Vollaard NB, Choueiri T, Wilson MT (2002) Exercise, free radicals and oxi- dative stress. Biochem Soc Trans 30: 280-285.

16. Dekkers JC, Van Doornen LJ, Kemper HC (1996) The role of antioxidant vitamins and en- zymes in the prevention of exercise-induced muscle damage. Sports Med 21: 213-238.

17. Aguilo A, Tauler P, Pilar GM, Villa G, Cordova A, et al. (2003) Effect of exercise intensity and training on antioxidants and cholesterol pro? le in cyclists. J Nutr Bio- chem 14: 319-325.

18. Mercken EM, Hageman GJ, Schols AMWJ, Akkermans MA, Bast A, et al. (2005) Rehabilitation decreases exercise-induced oxidative stress in chronic obstructive pulmonary disease. Am J Respir Crit Care Med 172: 994-1001.

19. Gerovasili V, Tripodaki E, Karatzanos E, Pitsolis T, Markaki V, et al. (2009) Short-term systemic effect of electrical muscle stimulation in critically ill patients. Chest 136: 1249-1256.

20. Brown MD, Jeal J, Bryant J, Gamble J (2001) Modification of microvasculaar filtration capacity in human limbs by training and electrical stimulation. Acta Physiol Scand 173: 359-368.

21. Hudlicka O, Brown MD, May S, Zakrzewicz A, Pries AR (2006) Changes in capillary shear stress in skeletal muscles exposed to long- term activity: role of NO. Microcirculation 13: 249-259.

22. Reese D, Shivapour ET, Wahls TL, Dudley-Javoroski SD, Shields R (2009) Neuromuscular electrical stimulation and dietary interventions to reduce oxidative stress in a secondary progressive multiple sclerosis patient leads to marked gains in function: a case report. Cases J 2: 7601. 